\title{
The Role of the Transradial Approach for Complex Coronary Interventions in Patients with Acute Coronary Syndrome
}

\author{
Sasko Kedev
}

Professor of Medicine, University Clinic of Cardiology, Medical Faculty, University of St Cyril and Methodius, Skopje, Macedonia

\begin{abstract}
Despite advances in antithrombotic and antiplatelet therapy, bleeding complications remain an important cause of morbidity and mortality in patients with acute coronary syndrome (ACS) undergoing percutaneous coronary intervention (PCI). A significant proportion of such bleedings are related to the access site, and adoption of transradial access (TRA) may reduce these complications. In patients with ST-segment elevation myocardial infarction (STEMI), TRA reduced cardiac mortality in comparison with the femoral approach (TFA). High-risk patients such as women, obese patients and elderly subjects who are at increased risk for vascular complications and bleeding, might particularly benefit from the TRA. However, specific radial expertise providing procedural time and a success rate comparable to those with the TFA are strongly recommended before using this technique in the emergency setting.
\end{abstract}

\section{Keywords}

Transradial approach, acute coronary syndrome, percutaneous coronary intervention, non-ST-segment elevation acute coronary syndromes, ST-segment elevation myocardial infarction, cardiogenic shock, left main culprit

Disclosure: The author has no conflicts of interest to declare.

Received: 15 May 2013 Accepted: 20 June 2013 Citation: Interventional Cardiology Review, 2013;8(2):81-6

Correspondence: Sasko Kedev, Professor of Medicine, University Clinic of Cardiology, Medical Faculty, University of St Cyril and Methodius, Vodnjanska 17, 1000 Skopje,

Macedonia. E: skedev@gmail.com

An invasive strategy including percutaneous coronary intervention (PCl) improves clinical outcomes in patients with ST-segment elevation myocardial infarction (STEMI) and in high-risk patients with non-ST-segment elevation acute coronary syndrome (NSTEACS). ${ }^{1,2}$ The femoral approach (TFA) is the preferred and most widely used percutaneous access site in most cardiac catheterisation laboratories worldwide. However, being a relatively deep and terminal vessel, the femoral artery may expose the patient to frequent bleeding and vascular complications, ${ }^{3,4}$ especially in the setting of acute coronary syndrome (ACS) where potent antithrombotic drugs are frequently used., 5

Since its initial description as a safe and feasible access route for cardiac catheterisation, ${ }^{7,8}$ the transradial access (TRA) has increasingly been used for $\mathrm{PCl}$. The main advantage over the TFA is a reduced risk of access site bleeding and major vascular complications, particularly in the presence of multiple and more powerful antiplatelet and antithrombotic agents. ${ }^{9}$ This is mainly ascribed to the more favourable anatomy of the radial artery that runs superficially, separated from major neurovascular structures, thus allowing shorter times to haemostasis and ambulation as compared with the TFA. ${ }^{10}$

More recently, the radial approach has been shown to confer mortality benefits for STEMI patients and a reduction in mortality, myocardial infarction (MI) and stroke for patients undergoing the procedure at high-volume radial centres. ${ }^{11-13}$

Reported access failure for radial procedures in primary $\mathrm{PCI}(\mathrm{PPCl})$ is low with an access crossover rate between $3.8 \%{ }^{14}$ and $9.6 \%{ }^{13}$ with negligible time delay by expert operators. There are several reasons leading to failure - inability to cannulate, severe radial artery spasm (RAS) and anatomical variations. In some of these difficult transradial cases, ulnar artery cannulation has been proposed as a reasonable and useful alternative to the TRA if performed by an experienced radial operator, before crossover to the TFA. ${ }^{15,16}$

\section{Bleeding Complications in Acute Coronary Syndrome}

Peri-PCl procedural bleeding complications have been consistently associated with worse outcomes and increased short- and longterm mortality. ${ }^{6,17}$ Access site-related bleeding, accounting for as many as $30-50 \%$ of all causes of bleeding in patients with ACS, has repeatedly been found to be the major contributor for bleeding events. ${ }^{9,18-20}$

Due to the firm link between bleeding, ischaemic events and mortality, more attention has recently been focused on bleeding avoidance strategies. ${ }^{21}$ Despite the development of new more potent, selective and safe antithrombotics, the use of TRA remains likely the best way to significantly influence access site-related bleeding risk.22-25

Recently, the REgistro regionale AngiopLastiche dell'Emilia-Romagna (REAL) Registry of 11,068 STEMI patients undergoing PPCl, showed that TRA was associated with a decreased two-year mortality rate compared with the traditional TFA (8.8 versus $11.4 \%$, hazard ratio [HR] 1.303; $p=0.025) .^{12}$ The observed difference in death was not explained by the incidence of Ml or stroke, which did not differ between groups. By 
Figure 1: Complete Thrombotic Occlusion of Unprotected Left Main in Patient Presenting with ST-segment Elevation Myocardial Infarction and Cardiogenic Shock - Right Radial Approach

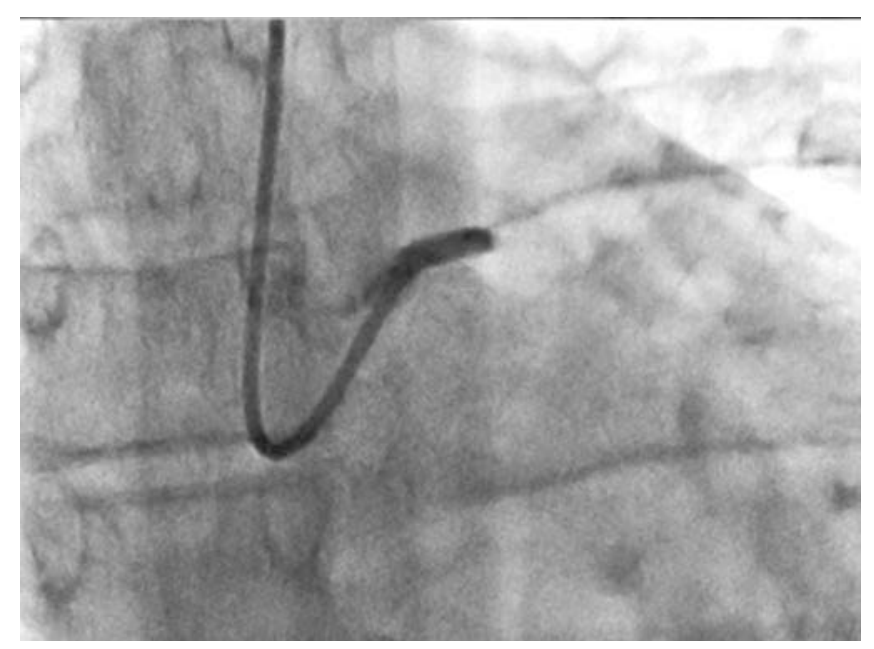

contrast, TRA was associated with a significant and marked reduction of in-hospital major bleeding or vascular events.

The available clinical evidence summarised in recent meta-analyses demonstrated a significant reduction in mortality, major adverse cardiac events (MACE), major bleeding events and major access site complications associated with the TRA..$^{24,25}$ Therefore, the use of the TRA for high-risk patients with ACS certainly has a key role in the prevention of access site bleeding complications.

\section{Randomised Controlled Trials and Registries of Transradial Access Versus the Femoral Approach in Acute Coronary Syndrome}

The radial versus femoral access for coronary angiography and intervention in patients with acute coronary syndromes (RIVAL) is the largest randomised comparison of radial and femoral artery access of 7,021 patients with ACS; 1,958 with a pre-randomisation diagnosis of STEMI; and 5,063 patients with NSTEACS. ${ }^{11}$ In patients with STEMI, TRA significantly reduced the primary outcome: death, $\mathrm{MI}$, stroke or non-coronary artery bypass graft surgery (CABG)-related major bleeding within 30 days ( 3.1 versus $5.2 \%$; HR 0.60; $p=0.026$ ) and mortality alone (1.3 versus $3.2 \%$; HR $0.39 ; p=0.006$ ). In patients presenting with NSTEACS, there were no significant differences in any of these outcomes. In both STEMI and NSTEACS patients, TRA reduced major vascular access site complications (1.4 versus $3.7 \%$; HR 0.37; $p<0.0001)$, and major bleeding as defined by the Acute Catheterization and Urgent Intervention Triage strategy (ACUITY) definition (1.9 versus $4.5 \%$; HR 043; $\mathrm{p}<0.0001$ ). In STEMI patients, the reduction in the primary and secondary composite outcomes was driven mainly by a reduction in mortality with a directionally consistent reduction in MI. No such benefit was observed in patients with NSTEACS. Access site crossover was higher in the radial group compared with the femoral group (7.6 versus $2.0 \%$; HR 3.82; $p<0.0001)$, and this was consistent in both STEMI and NSTEACS cohorts. ${ }^{26}$

The Radial Versus Femoral Randomized Investigation in ST Elevation Acute Coronary Syndrome (RIFLE-STEACS) is the first large randomised clinical trial of 1,001 patients with STEMI specifically designed to
Figure 2: Right Radial Access for Primary Percutaneous Coronary Intervention with 6F Extra Backup Guiding Catheter - Manual Thromboaspiration (Arrow) and Intra-aortic Balloon Pump Counterpulsation (Arrow) Through the Right Femoral Access

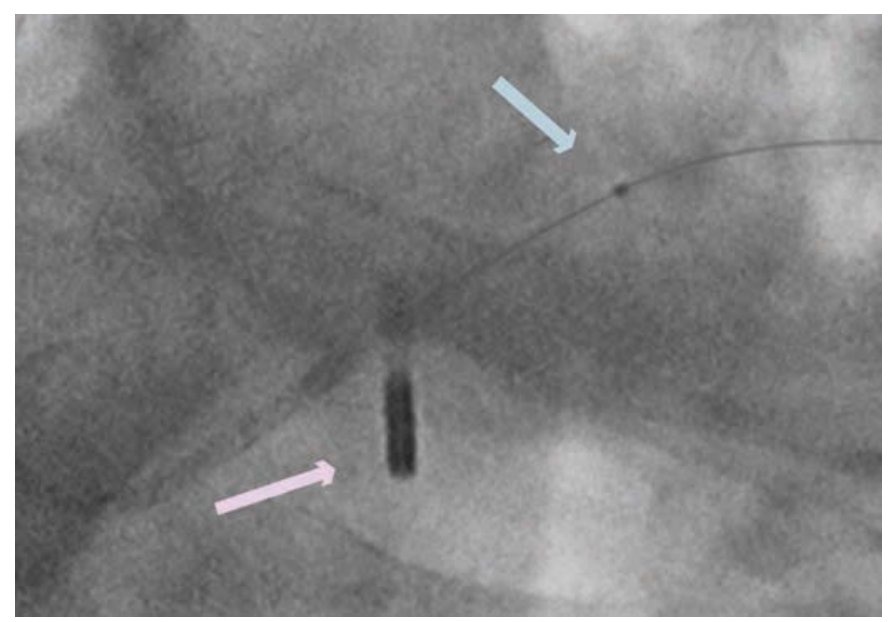

compare the radial (500 patients) and femoral approaches (501 patients) for primary/rescue PCI. In this nearly all-comers study, the TRA was associated with significantly lower rates of clinically relevant access site bleeding ( 2.6 versus $6.8 \% ; \mathrm{p}=0.002$ ) and subsequent 30-day mortality (5.2 versus $9.2 \% ; \mathrm{p}=0.020$ ) in comparison with TFA. The reduction in cardiac mortality and clinically relevant access site bleeding by $60 \%$ with a significant decrease in the need for transfusion in the radial arm of the RIFLE-STEACS, support the link between mortality and 'clinically relevant' access site bleeding. Furthermore, there were no differences in the symptom-to-balloon and door-to-balloon times between the two study groups. Vascular approach crossover was $9.6 \%$ in the radial arm and $2.8 \%$ in the femoral arm with negligible time delay by expert operators. ${ }^{13}$

Recently, A Prospective Randomized Trial of Radial vs. Femoral Access in Patients with ST-Segment Elevation Myocardial Infarction (STEMIRADIAL) showed that TRA was associated with a significantly lower incidence of major bleeding and access site complications, and a significantly better net clinical benefit - composite of death, $\mathrm{Ml}$ and stroke, and major bleeding (4.6 versus $11.0 \%$; $p=0.0028$ ) Moreover, TRA significantly reduced intensive coronary care unit (ICU) stay $(p=0.0016)$ and contrast volume $(p<0.01)$ compared with TFA. ${ }^{27}$

The post hoc analysis of the Harmonizing Outcomes With Revascularization and Stents in Acute Myocardial Infarction Trial (HORIZON-AMI), ${ }^{22}$ showed improved event-free survival in patients undergoing primary $\mathrm{PCl}$ by the TRA and confirmed the advantage of the TRA with regard to haemorrhagic complications also in patients treated with bivalirudin.

Based on data derived from the RIFLE-STEACS and STEMI subgroup of RIVAL, in the latest 2012 European Society of Cardiology (ESC) STEMI Guidelines recommendations, TRA is preferred over TFA if performed by an experienced operator (Class IIa, Level B). ${ }^{28}$

In a cohort of 21,339 patients suffering from STEMI in the Swedish Coronary Angiography and Angioplasty Registry (SCAAR), the adjusted one-year cumulative risk of death was lower in patients treated via TRA (odds ratio [OR] 0.78, 0.64-0.96; $p=0.018$ ). ${ }^{29}$ 
Figure 3 and 4: Final Result of Transradial Access Percutaneous Coronary Intervention with Drug-eluting Stent of Unprotected Left Main Culprit in Patient Presenting with ST-segment Elevation Myocardial Infarction and Cardiogenic Shock

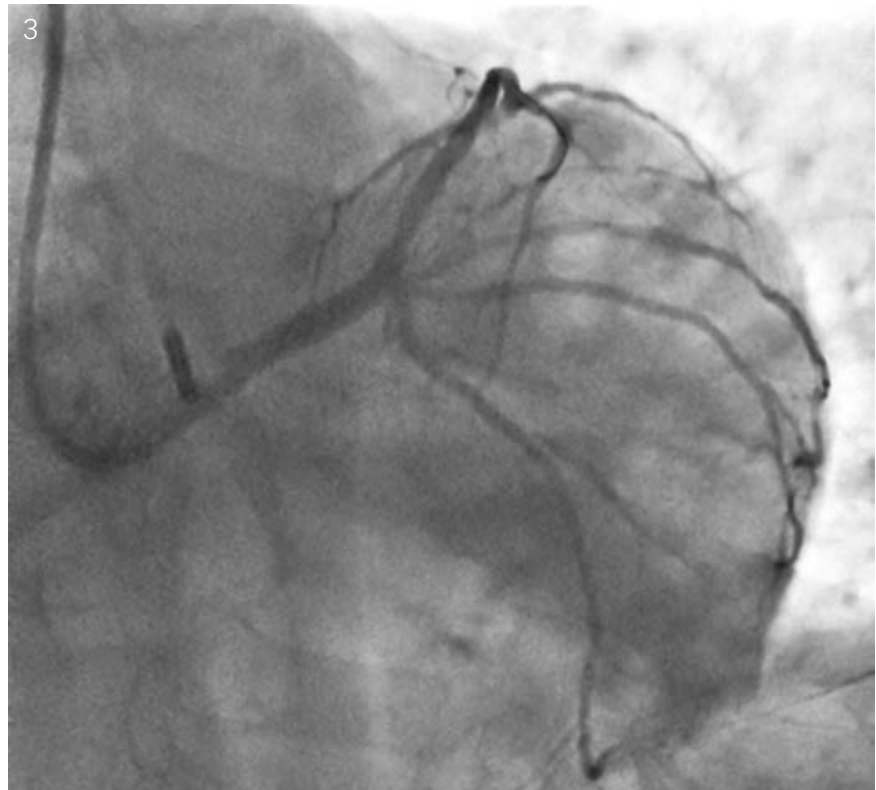

A recent meta-analysis of nine randomised controlled studies involving 2,977 patients suggested that the TRA is associated with a $47 \%$ reduction in mortality and a $38 \%$ reduction in major adverse cardiac events in STEMI patients undergoing PCl. ${ }^{24}$

Similarly, analysis of the North American National Cardiovascular Data Registry - CathPCI ${ }^{\circledR}$ Registry - that included 90,879 patients who underwent either primary or rescue PCI for STEMI showed that TRA was independently associated with the reduction of in-hospital mortality (OR 0.76, $95 \%$ confidence interval [Cl] 0.57-0.99) and of bleeding (OR 0.62, $95 \%$ Cl 0.53-0.72). ${ }^{30}$

Finally, the analysis of 46,128 PPCl cases recorded in the British Cardiovascular Intervention Society database over a five-year period, suggested that TRA was independently associated with a lower 30-day mortality (HR 0.71, $\mathrm{p}<0.05)$, in-hospital major adverse cardiac and cerebrovascular events (MACCE) (HR 0.73, $\mathrm{p}<0.05)$, major bleeding (HR $0.37, p<0.01$ ) and access site complications (HR 0.38, $p<0.01) .{ }^{31}$

However, the $0.7 \%$ absolute reduction in major bleeding and $0.3 \%$ absolute reduction in access site-related complications associated with TRA use cannot fully explain the scale of the mortality benefit associated with TRA in PPCl. ${ }^{31}$

Additional unmeasured factors may contribute to the benefit of TRA PCl. Although some access site complications will not result in significant blood loss, they may lead to systemic inflammation, activation of prothrombotic pathways and activation of the clotting cascade. This could further increase the risk of cardiovascular events even though the initial insult is not haemodynamically significant. ${ }^{32,33}$ Bleeding or access site complications can also lead to withdrawal of antiplatelet agents, increasing the risk of ischaemic complications.

\section{High-risk Subgroups for Bleeding and Vascular Complications}

Patients undergoing $\mathrm{PCl}$ in the context of ACS are expected to receive a combination of potent multiple antithrombotic drugs that

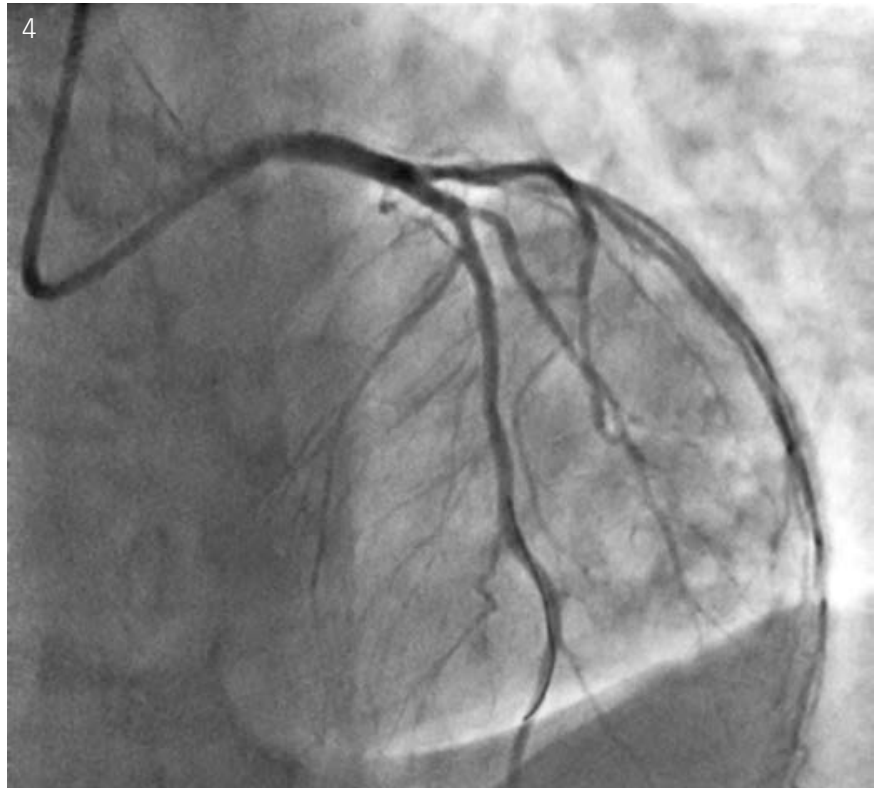

may lead to an increased risk of bleeding and subsequent morbidity and mortality.

Women are at higher risk of bleeding and other adverse outcomes after $\mathrm{PCl}$ than men. ${ }^{34,35}$ In a recent observational study, routine TRA was associated with reduced bleeding risk in women. ${ }^{36}$ Unfortunately, muscular arterial hyper-reactivity, procedural discomfort and small artery diameter increases the risk of first radial access failure $(9.6 \%$ in women versus $1.6 \%$ in men). However, successful radial access does not allow the operator to use more aggressive combinations of anticoagulants and antiplatelet agents in this group, given that women remain at higher non-access site bleeding risk. ${ }^{37,38}$

Elderly patients are also at high risk for bleeding and vascular complications post-PCl. Lower limb peripheral artery disease (PAD), tortuosity of the iliac arteries and aneurysms of the abdominal aorta may represent relative or absolute contraindications to TFA. As a result of PAD in the elderly, radial access appears to be as feasible as femoral access. In two randomised trials, the TRA was associated with fewer vascular complications in elderly patients. ${ }^{39,40}$

\section{Cardiogenic Shock and Left Main Culprit in Acute Coronary Syndrome}

Cardiogenic shock has a poor outcome compared with less severe presentations of ACS. The Should We Emergently Revascularize Occluded Coronaries for Cardiogenic Shock (SHOCK) trial ${ }^{40}$ showed the importance of revascularisation to improve outcomes, but the recent Intraaortic Balloon Pump in Cardiogenic Shock II (IABP-SHOCK II) trial ${ }^{41}$ failed to show any marginal benefit of adding haemodynamic support with intra-aortic balloon counterpulsation in the setting of shock.

Cardiogenic shock is associated with a doubling of the risk of bleeding compared with the absence of shock. ${ }^{42}$ There may be a safety advantage of using the radial artery for the coronary intervention and reserving the femoral artery for larger devices in patients with cardiogenic shock (see Figures 1-4). 
Rodriguez-Leor analysed their single-centre registry experience with radial access in cardiogenic shock patients. From a 1,400-patient experience, 122 (8.7 \%) developed cardiogenic shock with 80 undergoing transfemoral and the remaining 42 undergoing transradial catheterisation. Mortality (64.3 versus $32.5 \%, p<0.001$ ), serious access site complications (11.9 versus $2.5 \%, p<0.03$ ), access site complications requiring blood transfusion (7.1 versus $0.0 \%, p<0.04$ ) and MACCE (death, infarction, stroke, serious bleeding and postanoxic encephalopathy) (73.8 versus $43.8 \%, p<0.001$ ) were greater in patients treated by the femoral route. After multivariate analysis, initial TRA was associated with lower mortality (OR 0.39; $95 \%$ Cl 0.15-0.97) compared with an initial TFA. ${ }^{43}$

Bernat et al. evaluated outcomes of 197 STEMI patients with signs of cardiogenic shock who were treated with primary $\mathrm{PCl}$ at two highvolume centres. The TRA was used successfully in $55 \%$ of cases where at least one radial artery was weakly palpable. TRA emerged as an independent predictor of survival with more than half of the patients treated successfully. Mortality at one-year was $44 \%$ in the radial group and $64 \%$ in the femoral group $(p=0.0044){ }^{44}$

Romagnoli et al. analysed 241 consecutive patients ( $91 \%$ with ACS and left main culprit in $26 \%$ of cases) receiving IABP support during $\mathrm{PCl}$ in four high-volume centres. Patients were further divided in two groups - 116 patients receiving double femoral access (FF) and 125 receiving both radial and femoral (RF) approaches. NACEs were more frequent in the FF group when compared with the RF group (67 versus $41 \%, p<0.01)$. In particular, this difference originated from an increase of access site-related bleeding ( 21 versus $7 \%, p<0.01$ ) and cardiac death (41 versus $25 \%, p<0.01$ ). ${ }^{45}$ These data show that a radial-femoral access strategy is safer than a femoral-femoral access strategy, and this safety advantage is associated with reduced mortality. ${ }^{45}$

\section{Left Main Culprit}

A significant involvement of the left main coronary artery occurs in $4-7 \%$ of patients presenting with an acute myocardial infarction (AMI). ${ }^{46,47}$ These critically ill patients frequently present with cardiogenic shock or cardiac arrest and are at high risk for in-hospital major cardiac adverse events. ${ }^{48,49}$

Primary PCI for an AMI due to an unprotected left main coronary artery (ULMCA) culprit lesion is a rare procedure, frequently associated with adverse clinical outcomes. The incidence of AMI due to an ULMCA culprit lesion is reported to be $0.8-5.4 \%{ }^{50}$

Patients undergoing primary $\mathrm{PCl}$ for an $\mathrm{AMI}$ due to an ULMCA culprit lesion and presenting with cardiogenic shock have a high 30-day mortality compared with patients without cardiogenic shock, with the estimated 30-day all-cause mortality of $55 \%$ for patients with cardiogenic shock and $15 \%$ for patients without cardiogenic shock. A hybrid approach of initial revascularisation by primary $\mathrm{PCl}$ and elective surgery afterwards remains an alternative treatment option.

Treating patients with cardiogenic shock or after cardiac arrest is one of the most challenging $\mathrm{PCl}$ procedures due to the nature of the clinical presentation while targeting a coronary lesion associated with a very large area of the myocardium at risk. These haemodynamically unstable patients have an extensive amount of ischaemic myocardium. Immediate mechanical haemodynamic support may prevent from further multi-organ failure.
Whether newer and more powerful circulatory assist devices (Impella $₫$, TandemHeart $\AA$, Extracorporeal Membrane Oxygenation [ECMO]) will result in better outcomes is the subject of ongoing clinical evaluation before widespread adoption. ${ }^{51}$

Most PCIs in high-risk ACS patients can be performed by TRA through conventional 6 French (Fr) guiding catheters, including complex cases, left main bifurcations and cardiogenic shock. However, a stepwise approach to learning is proposed and high-risk ACS-PCI is recommended as the last step.

Ultimately, the treatment of patients in shock requires an individualised approach. Although the radial pulse may return with vasopressor administration, there may be clinical situations in which radial access is not possible and femoral access must be used. From the available evidence supporting the safety of the TRA over the TFA, a 'radial first' strategy likely still applies in most patients, even those with large STEMI and shock if performed by a skilled and experienced radial operator. Haemodynamic support devices can be placed via the femoral route and temporary pacemakers can be placed through the forearm or femoral veins (see Figures 1-4). ${ }^{52}$

\section{UInar Artery Access}

The TRA may be difficult or associated with increased risk of complications in the presence of significant radial artery abnormalities, severe loops and curvatures, after failed radial artery cannulation and when the radial artery was repeatedly used previously.

Transulnar artery cannulation (TUA) has been proposed as an alternative access for interventions in patients with a small-calibre radial artery or a thin radial pulse and stronger pulsation of the ulnar artery. Larger studies have further confirmed the safety and effectiveness of TUA as an alternative wrist approach to TRA for coronary interventions. ${ }^{16,53}$

The procedural success, advantages and complication rates for transulnar interventions appear similar to those from the TRA. ${ }^{15,53}$ Adding the ulnar artery access expertise could further reduce the crossover rate to TFA and lower the intrinsic risk of bleeding and vascular complications associated with the TFA. When the TRA is not possible or fails, the TUA may be considered as a safe alternative before reverting to the TFA. ${ }^{16}$ The TUA is a viable option for the high-volume radial centres, when performed by the expert radial operators who are skilled in ulnar artery cannulation. ${ }^{53}$

\section{Limitations of the Transradial Access for Complex Percutaneous Coronary Intervention in Acute Coronary Syndrome}

Longer procedure duration and radiation exposure during the learning curve, and the potential influence on radial artery patency have slowed down acceptance of the TRA. Technique of TRA requires a specific set of skills, and is associated with a significant learning curve. With appropriate training, similar success rates with the TRA and TFA may be achieved even in complex ACS cases. The learning curve is highly individual and more experienced operators may become proficient sooner.

To achieve the best results in TRA interventions, individual operators and institutional teams should aim at maintaining the highest feasible rate of TRA. After the learning curve has been completed, for over 
$50 \%$ TRA in routine practice, a minimum of 80 procedures per year per operator is recommended. ${ }^{54}$

A stepwise approach to learning is proposed according to clinical characteristics and $\mathrm{PCl}$ difficulty. ACS-PCl is proposed as the last step (NSTEACS and STEMI patients), due to multifaceted clinical settings and $\mathrm{PCl}$ complexity. The highest level of competency is obtained when patients requiring complex clinical management can be managed with timely and technically proficient control of $\mathrm{PCl}$, irrespective of vascular access anatomy. ${ }^{54}$

The TRA is associated with very low incidence $(0.2 \%)$ of major vascular complications. ${ }^{10}$ Haematomas are usually minor, affecting only subcutaneous tissue. Unlike groin bleeding, subcutaneous bleeding after TRA is rapidly noticed and can be controlled by local compression. Major vascular complications like compartment syndrome are completely avoidable.

Radial artery occlusion (RAO) is the most common complication, affecting 1.5-33.0\% shortly after the procedure, depending on the antithrombotic regimen, sheath size and protocol for haemostasis..$^{55}$ Although usually asymptomatic, RAO is an important consequence of TRA, as it prohibits future ipsilateral TRA. Preserving radial artery patency is of paramount importance. Proper anticoagulation, downsizing of material (sheathless catheters) and shorter and less forceful 'patent haemostasis' of the radial artery with the emphasis on maintaining adequate arterial flow, considerably reduces the risk of RAO. It is important to remember that almost all potential complications are preventable by accurate preprocedural evaluation, meticulous technique and optimal post-procedural management.

The incidence of RAS has varied considerably (4-30\%) depending on its definition, study population and the expertise of the operators..$^{54}$ Spasm is the second most common cause of radial access failure after anatomical variations. The incidence of moderate/severe RAS is low in centres with a default TRA ( $2.7 \%)$. Its development and procedural failure $(0.7 \%)$ appears strongly related to the numbers of puncture attempts and the use of larger-bore sheaths. ${ }^{56}$

\section{Technical Recommendations for Complex Percutaneous Coronary Intervention in Acute Coronary Syndrome}

Challenging anatomy must be avoided to minimise the risk of complications and shorten the duration of both the procedure and radiation exposure. For this reason, a systematic preliminary angiogram of the forearm arteries through the radial introducer is recommended.

The final choice of procedure will depend on the level of expertise of the operator, and the equipment required. In patients with cardiogenic shock, TRA procedures can be performed if the radial artery is palpable while leaving two potential femoral accesses for IABP counterpulsation or more complex cardiac-assist devices (see Figures 1-4).

The right side is usually more ergonomic to the operator; however, the left radial approach might be more convenient in the learning phase because of similar catheter handling when compared to the femoral approach. Even if dedicated catheter shapes are available, traditional femoral shapes accommodate the radial approach easily. Coaxial alignment with the target coronary artery is mandatory and requires different handling for the right radial versus femoral approach.

The choice of guiding catheter (diameter, shape, size) is essential for adequate back-up. Most PCIs can be performed through 6 Fr guiding catheters, including complex cases, thrombus aspiration, post-CABG and left main bifurcations.

In selected patients of large stature, larger catheters (7 or even $8 \mathrm{Fr}$ ) or sheathless guiding catheters can be considered, allowing for large-lumen guiding catheters to be used in a small radial artery. However, these catheters, though useful in selected cases, are more difficult to handle in complex procedures due to lower back-up.

RAO should be prevented during and after the procedure with systematic assessment of the arterial patency. ${ }^{57}$ Spasm prevention with 3-5 milligrams ( $\mathrm{mg}$ ) verapamil administered intra-arterially through the sheath is routinely recommended. Specific early and delayed post-procedural attention to forearm haematomas is mandatory.

\section{Conclusion}

Considerable evidence supports conversion to TRA for most $\mathrm{PCl}$ procedures in ACS, with an emphasis on decreasing access site bleeding and vascular complications without compromising procedural outcome. Beside the development of new more selective and safe antithrombotic agents, the use of TRA remains likely the best way to significantly affect access site-related bleeding risk. A high-risk subset of patients for bleeding and vascular complications such as complex STEMI patients, women and the elderly, might particularly benefit from the TRA whenever appropriately available and performed by skilled operators.

Complications arising from the TRA are infrequent, negligible and mostly avoidable compared with TFA complications. Certain limitations to the TRA such as longer radiation exposure during the learning curve and the potential influence on radial artery patency have slowed down acceptance of this technique. Therefore, the modern interventional cardiologist should go through a high-volume radial training programme, and after developing the optimal radial expertise, adopt 'the TRA first' whenever possible. Adding the ulnar artery access expertise could further reduce the crossover rate to TFA, and lower the intrinsic risk of bleeding and vascular complications associated with TFA. Femoral approach will likely remain the viable alternative for patients not eligible for the wrist access and accessory access for larger devices in patients with cardiogenic shock. Complex PCIs in patients with ACS, cardiogenic shock and left main culprit, should be performed only by experienced high-volume radialists.

Finally, it is important to remember that the choice of access site is only one aspect of improving the patient's outcome. All interventions should be performed according to the highest available standards, providing the best care for each individual patient without sacrificing procedural success and long-term prognosis.
1. Keeley $\mathrm{EC}$, Boura JA, Grines $\mathrm{CL}$, Primary angioplasty versus intra-venous thrombolytic therapy for acute myocardial infarction: a quantitative review of 23 randomised trials, Lancet, 2003;361:13-20
2. Mehta SR, Cannon CP, Fox KA, et al., Routine vs selective invasive strategies in patients with acute coronary syndromes: a collaborative meta-analysis of randomized trials, JAMA, 2005;293:2908-17.
3. Doyle BJ, Ting HH, Bell MR, et al., Major femoral bleeding complications after percutaneous coronary intervention: incidence, predictors, and impact on long-term survival among 17,901 patients treated at the Mayo Clinic from 1994 
to 2005, JACC Cardiovasc Interv, 2008;1:202-9.

4. Elbarouni B, Elmanfud O, Yan RT, et al., Temporal trend of in-hospital major bleeding among patients with no ST-elevation acute coronary syndromes, Am Heart J, 2010;160:420-7.

5. Steg PG, Huber K, Andreotti F, et al., Bleeding in acute coronary syndromes and percutaneous coronary interventions: position paper by the Working Group on Thrombosis of the European Society of Cardiology, Eur Heart J, 2011;32:1854-64

6. Mehran R, Pocock SJ, Stone GW, et al., Associations of major bleeding and myocardial infarction with the incidence and timing of mortality in patients presenting with non-STelevation acute coronary syndromes: a risk model from the ACUITY trial, Eur Heart J, 2009:30:1457-66.

7. Campeau L, Percutaneous radial artery approach for coronary angiography, Cathet Cardiovasc Diagn, 1989;16:3-7.

8. Kiemeneij F, Laarman GJ, Percutaneous transradial artery approach for coronary stent implantation, Cathet Cardiovasc Diagn, 1993;30:173-8.

9. Rao SV, Ou FS, Wang TY, et al., Trends in the prevalence and outcomes of radial and femoral approaches to percutaneous coronary intervention: a report from the percutaneous coronary intervention: a report from the
National Cardiovascular Data Registry, JACC Cardiovasc Interv, 2008;1:379-86.

10. Kiemeneij F, Laarman GJ, Odekerken D, et al., A randomized comparison of percutaneous transluminal coronary angioplasty by the radial, brachial and femoral approaches: the access study, J Am Coll Cardiol, 1997:29:1269-75.

11. Jolly SS, Yusuf S, Cairns J, et al., Radial versus femora access for coronary angiography and intervention in patients with acute coronary syndromes (RIVAL): a randomised, parallel group, multicentre trial, Lancet, 2011;377:1409-20.

12. Valgimigli M, Saia F, Guastaroba P, et al., Transradial versus transfemoral intervention for acute myocardial infarction. A propensity score- adjusted and -matched analysis from the REAL (REgistro regionale Angioplastiche dell'Emilia-Romagna) multicenter registry, J Am Coll Cardiol Intv, 2012;5:23-35.

13. Romagnoli E, Biondi-Zoccai G, Sciahbasi A, et al., Radial versus femoral randomized investigation in ST-segment elevation acute coronary syndrome: the RIFLE-STEACS (Radial Versus Femoral Randomized Investigation in ST-Elevation Acute Coronary Syndrome) study, I Am Coll Cardiol, 2012;60:2481-9.

14. Vink MA, Amoroso G, Dirksen MT, et al., Routine use of the transradial approach in primary percutaneous coronary intervention: procedural aspects and outcomes in 2209 patients treated in a single high-volume centre, Heart 2011;97:1938-42.

15. Kedev S, Transulnar approach: Pros and Cons. In: Pate $\mathrm{T}(\mathrm{ed})$, Patel's Atlas of Transradial Intervention The Basics and Beyond, Malvern PA, US, HMP Communications, 2012;221-32.

16. de Andrade PB, Tebet MA, Nogueira EF, et al., Transulnar approach as an alternative access site for coronary invasive procedures after transradial approach failure, Am Heart I, 2012;164:462-7.

17. Fuchs $\mathrm{S}$, Kornowski R, Teplitsky I, et al., Major bleeding complicating contemporary primary percutaneous coronary interventions-incidence, predictors, and prognostic implications, Cardiovasc Revasc Med, 2009;10:88-93.

18. Applegate RJ, Sacrinty MT, Kutcher MA, et al., Trends in vascular complications after diagnostic cardiac catheterization and percutaneous coronary intervention via the femoral artery, 1998 to 2007, JACC Cardiovasc Interv, 2008:1:317-26

19. Verheugt FW, Steinhubl SR, Hamon M, et al., Incidence, prognostic impact, and influence of antithrombotic therap on access and non- access site bleeding in percutaneous coronary intervention, JACC Cardiovasc Interv, 2011;4:191-7.

20. Hermanides RS, Ottervanger JP, Dambrink JH, et al., Incidence, predictors and prognostic importance of bleeding after primary PCI for ST-elevation myocardial infarction, Eurolntervention, 2010;6:106-11.

21. Budaj A, Eikelboom JW, Mehta SR, et al., Improving clinical outcomes by reducing bleeding in patients with non-ST-elevation acute coronary syndromes, Eur Heart J, 2009;30:655-61.

22. Généreux P, Mehran R, Palmerini T, et al., Radial access in patients with ST-segment elevation myocardial infarction undergoing primary angioplasty in acute myocardia infarction: the HORIZONS-AMI trial, Eurolntervention, 2011;7:905-16.

23. Jolly SS, Amlani S, Hamon M, et al., Radial versus femora access for coronary angiography or intervention and the impact on major bleeding and ischemic events: a systematic review and meta-analysis of randomized trials, Am Heart I, 2009:157:132-40.

24. Mamas MA, Ratib K, Routledge $\mathrm{H}$, et al., Influence of access site selection on $\mathrm{PCl}$-related adverse events in patients with STEMI: meta-analysis of randomised controlled trials, Heart, 2012;98:303-11.

25. Bertrand OF, Bélisle P, Joyal D, et al., Comparison of transradial and femoral approaches for percutaneous coronary interventions: a systematic review and hierarchical Bayesian meta-analysis, Am Heart J, 2012;163:632-48.

26. Mehta SR, Jolly SS, Cairns J, et al., Effects of radial versus femoral artery access in patients with acute coronary syndromes with or without ST-segment elevation, J Am Coll Cardiol, 2012;60(24):2490-9.

27. Bernat I, STEMI-RADIAL: A prospective, randomized trial of radial vs. femoral access in patients with ST-Segment elevation myocardial infarction, Presented at: TCT 2012, Miami, FL, US, 26 October 2012.

28. Steg PG, James SK, Atar D, et al., ESC Guidelines for the management of acute myocardial infarction in patients presenting with ST-segment elevation, Eur Heart J, 2012;33:2569-619.

29. Olivecrona GK, Lagerqvist B, Gotberg M, et al., Lower Mortality with Transradial $\mathrm{PCl}$ Compared to Transfemoral PCl in 21000 Patients with Acute Myocardial Infarction-Results from the SCAAR Database, Presented at: EuroPCR 2011, Paris, France, 17-20 May 2011

30. Baklanov DV, Kaltenbach $\perp A$, Marso SP, et al., The prevalence and outcomes of transradial percutaneous coronary intervention for ST-segment elevation myocardial infarction: analysis from the National Cardiovascular Data Registry (2007 to 2011), J Am Coll Cardiol, 2013;61:420-6.

31. Mamas AM, Ratib K, Routledge $H$, et al., Influence of arterial access site selection on outcomes in primary percutaneous coronary intervention: are the results of randomized trials achievable in clinical practice?, JACC Cardiovasc Interv, 2013;6:698-706.

32. Doyle BJ, Rihal CS, Gastineau DA, Holmes DR Jr, Bleeding blood transfusion, and increased mortality after percutaneous coronary intervention: implications for contemporary practice, J Am Coll Cardiol, 2009;53:2019-27.

33. Allen C, Glasziou P, Del Mar C, Bed rest: a potentially harmful treatment needing more careful evaluation, Lancet, 1999;354:1229-33.

34. Chauhan MS, Ho KK, Baim DS, et al., Effect of gender on in-hospital and one-year outcomes after contemporary coronary artery stenting, Am J Cardiol, 2005;95:101-4.

35. Nikolsky E, Mehran R, Dangas G, et al., Development and validation of a prognostic risk score for major bleeding in patients undergoing percutaneous coronary intervention via the femoral approach, Eur Heart J, 2007;28:1936-45.

36. Pristipino C, Pelliccia F, Granatelli A, et al., Comparison of access-related bleeding complications in women versus men undergoing percutaneous coronary catheterization using the radial versus femoral artery, Am I Cardiol, using the radial vers

37. Valsecchi $O$, Musumeci G, Vassileva A, et al., Safety and feasibility of transradial coronary angioplasty in elderly patients, Ital Heart J, 2004;5:926-31.

38. Louvard Y, Benamer H, Garot P, et al., Comparison of transradial and transfemoral approaches for coronary angiography and angioplasty in octogenarians (the OCTOPLUS study), Am J Cardiol, 2004;94:1177-80.

39. Achenbach $S$, Ropers D, Kallert L, et al., Transradial versus transfemoral approach for coronary angiography and intervention in patients above 75 years of age, Catheter Cardiovasc Interv, 2008;72:629-35.

40. Hochman JS, Sleeper LA, Webb JG, et al., Early revascularization in acute myocardial infarction complicated by cardiogenic shock. SHOCK Investigators. Should We Emergently Revascularize Occluded Coronaries for Cardiogenic Shock, N Engl J Med, 1999;341:625-34.

41. Thiele H, Zeymer U, Neumann FJ, et al., Intraaortic balloon support for myocardial infarction with cardiogenic shock, N Engl J Med, 2012;367:1287-96.

42. Mehta SK, Frutkin AD, Lindsey JB, et al., Bleeding in patients undergoing percutaneous coronary intervention: the development of a clinical risk algorithm from the National Cardiovascular Data Registry, Circ Cardiovasc Interv, 2009;2:222-9.

43. Rodriguez-Leor O, Fernandez-Nofrerias E, Carrillo X, et al., Transradial percutaneous coronary intervention in cardiogenic shock: a single-center experience, Am Heart J, 2013;165:280-5

44. Bernat I, Abdelaal E, Plourde G, et al., Early and late outcomes after primary percutaneous coronary intervention by radial or femoral approach in patients presenting in acute ST-elevation myocardial infarction and cardiogenic shock, Am Heart J, 2013;165(3):338-43.

45. Romagnoli E, De Vita M, Burzotta F, et al., TCT-31 Clinical Benefit of Radial Versus Femoral Approach in Percutaneous Coronary Intervention with Intra-Aortic Balloon Pump Support, I Am Coll Cardiol, 2012;60/17/Suppl B9-10.

46. Goldberg $\mathrm{S}$, Grossman W, Markis JE, et al., Total occlusion of the left main coronary artery. A clinical, hemodynamic and angiographic profile, Am J Med, 1978;64:3-8.

47. Spiecker M, Erbel R, Rupprecht HJ, Meyer J, Emergency angioplasty of totally occluded left main coronary artery in acute myocardial infarction and unstable angina pectoris-institutional experience and literature review, Eur Heart J, 1994;15:602-7.

48. de Feyter PJ, Serruys PW, Thrombolysis of acute total occlusion of the left main coronary artery in evolving myocardial infarction, Am J Cardiol 1984:53:1727-8.

49. Quigley RL, Milano CA, Smith LR, et al., Prognosis and management of anterolateral myocardial infarction in patients with severe left main disease and cardiogenic shock. The left main shock syndrome, Circulation, 1993;88:II65-70.

50. Vis MM, Beijk MA, Grundeken MJ, et al., A systematic review and meta-analysis on primary percutaneous coronary intervention of an unprotected left main coronary artery culprit lesion in the setting of acute myocardial infarction, JACC Cardiovasc Interv, 2013;6:317-24.

51. Basra SS, Loyalka P, Kar B, Current status of percutaneous ventricular assist devices for cardiogenic shock, Curr Opin Cardiol, 2011;26:548-54.

52. Gilchrist IC, Rao SV, Improving outcomes in patients with cardiogenic shock. achieving more through less, Am Heart 2013;165(3):256-7.

53. Kedev S, Zafirovska B, Dharma S, Petkoska D, Safety and feasibility of transulnar catheterization when ipsilateral radial access is not available, Catheter Cardiovasc Interv 2013 [Epub ahead of print].

54. Hamon M, Pristipino C, Di Mario C, et al., Consensus document on the radial approach in percutaneous cardiovascular interventions: position paper by the EAPCI and Working Groups on Acute Cardiac Care and Thrombosis of the European Society of Cardiology, Eurolntervention, 2013;8:1242-51.

55. Geijer H, Persliden J, Radiation exposure and patient experience during percutaneous coronary intervention using radial and femoral artery access, Eur Radiol, 2004;14:1674-80

56. Goldsmit A, Kiemeneij F, Gilchrist IC, et al., Radial artery spasm associated with transradial cardiovascular procedures: Results from the RAS registry, Catheter Cardiovasc Interv, 2013 [Epub ahead of print].

57. Pancholy SB, Patel TM, Effect of duration of hemostatic compression on radial artery occlusion after transradial access, Catheter Cardiovasc Interv, 2012;79:78-81. 